\title{
When Grilli and Yang meet Prebisch and Singer: Piecewise linear trends in primary commodity prices
}

\author{
Hiroshi Yamada* \\ Department of Economics \\ Hiroshima University \\ Higashi-Hiroshima, Japan \\ $739-8525$
}

\author{
Gawon Yoon $^{\dagger}$ \\ Department of Economics \\ Kookmin University \\ Seoul, S. Korea \\ 136-702
}

March 3, 2013

\begin{abstract}
In this study, we test the Prebisch-Singer hypothesis on the secular decline of relative primary commodity prices with the extended Grilli and Yang (1988) data set, ending at 2010. Rather than asking whether it holds for the whole sample period, we examine if the hypothesis holds sometimes during the sample period by estimating the piecewise linear trends of primary commodity prices. We employ the new $\ell_{1}$ trend filtering proposed by Kim et al. (2009) to estimate the piecewise linear trends. We find that the PrebischSinger hypothesis holds sometimes, but not always, for many of the primary commodities in the Grilli-Yang data. The strength of the Prebisch-Singer hypothesis has become substantially weaker recently, as the relative prices of many primary commodities have increased sharply since around 2000 .
\end{abstract}

Keywords: Prebisch-Singer hypothesis, primary commodity prices, $\ell_{1}$ trend filtering, piecewise linear trends

JEL classification: Q11, C22, O13, F1

\footnotetext{
*Tel.: +81-82-424-7214, Fax: +81-82-424-7212, yamada@hiroshima-u.ac.jp. Hiroshi Yamada thanks the Japan Society for the Promotion of Science (JSPS) for its financial support (KAKENHI 22530272).

${ }^{\dagger}$ Tel.: +82-2-910-4532, Fax: +82-2-910-4519, gyoon@kookmin.ac.kr, corresponding author. Gawon Yoon's work was supported by the Research Program of Kookmin University in Korea.
} 


\section{Introduction}

Over two decades ago, Grilli and Yang (1988) compiled primary commodity price indexes and tested the hypothesis put forward by Raúl Prebisch and Hans Singer. The so-called Prebisch-Singer hypothesis concerns the secular decline of the terms of trade of primary commodity prices relative to those of manufactured goods. For instance, Prebisch (1950, p. 4) found that "the price relation turned steadily against primary production from the 1870's until the Second World War." Singer (1950, p. 477) also noted that "It is a matter of historical fact that ever since the [eighteen] seventies the trend of prices has been heavily against sellers of food and raw materials and in favor of the sellers of manufactured articles." Grilli and Yang (1988) built "a U.S. dollar index of prices of twenty-four internationally traded nonfuel commodities, beginning in 1900." The original data series ended at 1986, but it is still regularly updated; see Pfaffenzeller et al. (2007). The current incarnation includes observations up to 2010. The Grilli-Yang data set is widely employed in international trade and economic development studies. There are numerous works that employ the data to examine the validity of the Prebisch-Singer hypothesis; see, for instance, Cuddington et al. (2007) for a survey.

It is not easy to estimate the trend components of the primary commodity prices because the prices are volatile and the changes in their trends, if any, are relatively small; see Cashin and McDermott (2002). Furthermore, Deaton (1999) remarked that "commodity prices lack in trend." Previous works found only a relatively small number of negative trends in the data. For instance, Kim et al. (2003) found strong evidence for negative trends for at most three commodities out of twenty-four: aluminum, hides, and rice for the sample ending at 1998. Moderately strong evidence was found for sugar and wheat. Interestingly, they showed that lamb and timber exhibited positive trends during the entire sample period. In a new study, Harvey et al. $(2010,2012)$ found negative trends only for the following five commodities: aluminum, banana, rice, sugar, and tea. In contrast, tobacco had a significant positive trend for the full sample period. Their sample ended at 2003. 
Both Kim et al. (2003) and Harvey et al. (2010, 2012) considered the presence of linear trends for the whole sample periods. Even though the Prebisch-Singer hypothesis postulates negative trends for relative primary commodity prices, we should also expect that they may exhibit changing trends and even positive trends for at least some of the sample periods. For instance, major wars like World Wars I and II and numerous local wars increased demand for raw materials and caused some of their prices to skyrocket. Occasional droughts also increased the prices of agricultural goods. A small number of multinational cooperations had control of the supply of some metals and, consequently, their prices had increased over the years. Eventually, they lost control and the prices declined.

Grilli and Yang (1988) already acknowledged the possibility that the trends of relative primary commodity prices are not monotone, but changing over time. They used piecewise linear regressions with dummy variables to monitor the structural changes in the trend functions of commodity prices. They considered one-time structural breaks only at a priori chosen dates. Grilli and Yang (1988) found, however, little evidence for structural breaks among their aggregate commodity price indexes.

In this study, we continue their efforts to estimate the structural changes in the trend functions of primary commodity prices with the extended Grilli-Yang data set, ending at 2010. To estimate the trend components, we employ a novel approach. We apply the new $\ell_{1}$ trend filtering, proposed by Kim et al. (2009) to estimate the trends of primary commodity prices. A notable feature of the approach is that it yields piecewise linear trend functions of time, without specifying the location and number of breaks a priori.

We find that only one commodity had a negatively sloped trend function throughout the whole sample period. Therefore, there is virtually no evidence that the Prebisch-Singer hypothesis always holds in the extended Grilli-Yang data set. Most commodities exhibited negatively sloped trends during some of the sample periods. Consequently, we find strong evidence that the Prebisch-Singer hypothesis holds sometimes, although not always. Furthermore, the strength of the hypothesis became substantially weaker during the last decade, as 
the relative prices of many of the primary commodities had increased in recent years. Overall, we can tell more about the dynamics of relative primary commodity prices by estimating their piecewise linear trends with the new $\ell_{1}$ trend filtering method. We would like to add that in this study we examine only the presence of negative trends in primary commodity prices. For instance, we do not study what determine their changing trends and discuss the policy implications for commodity producing countries. Deaton (1999) and Tilton (2012) contain some interesting discussions on these subjects.

The remainder of this study is organized as follows: in the next section, we document the Grilli and Yang's (1988) main arguments as to why we should expect structural changes in the trend functions of primary commodity prices. In section 3 , we introduce the new $\ell_{1}$ trend filtering approach proposed by Kim et al. (2009) to estimate the trend components of commodity prices. We also discuss some properties of the $\ell_{1}$ trend filtering, which remains relatively unknown in the current economic literature. In section 4, our main empirical results are presented. We employ the extended Grilli-Yang data series with twenty-four primary commodity prices and eight aggregate prices, ending at 2010. Finally, concluding remarks are provided in section 5 .

\section{Changing trends in primary commodity prices}

Grilli and Yang (1988) acknowledged the possibility that the trends of relative primary commodity prices may change over time. For instance, they noted that,

- "The negative trend present in the relative prices of metals from 1900 to $1986 \ldots$ is not uniform over time. A clear break in the price trend occurs in the early 1940s" (p. 18).

- "It was in the mid-1950s that petroleum-based synthetic products began to exercise strong downward pressure on natural rubber and natural fiber prices (cotton, jute, wool)" (p. 18).

Furthermore, Grilli and Yang (1988) allowed multiple breaks in trends as well. For instance, 
- "From 1900 to about 1941, the GYCPIM/MUV shows a strong negative trend (1.7 percent a year). Between 1942 and 1986 the trend turns positive (0.5 percent a year). The rising trend of the GYCPIM/MUV after 1941 was even stronger until the early 1970 s"1 (p. 18).

- "An example of this can be found in the trend in the relative prices of metals in the 1900-86 period, which shows a clear primary tendency to fall, but a secondary tendency in the opposite direction" (p. 30).

- "Metals, conversely, though showing the strongest overall negative trend in their relative prices over the current century, did experience a precipitous fall until the early 1940s and a strong inversion of that tendency since then" (p. 34).

Consequently, Grilli and Yang (1988) considered a quadratic trend for the relative prices of metals as "the result of two sets of forces affecting their long-run costs of production." They found, however, only weak empirical evidence for the quadratic trend. In contrast, Harvey et al. (2011) found recently the presence of quadratic trends in many of the primary commodity prices. $^{2}$ Grilli and Yang (1988) also tested the presence of one-time structural breaks in their relative aggregate primary commodity price index, GYCPI/MUV, at a priori known dates. They found, however, little evidence for structural breaks. ${ }^{3}$

Employing a variety of unit root tests that allow structural breaks in the trend functions, many recent studies also examine the validity of the Prebisch-Singer hypothesis. For instance, Kellard and Wohar (2006) allowed (up to) two structural breaks. They found considerably less support for the hypothesis with the unit root test proposed by Lumsdaine and Papell (1997). Their sample period is $1900-1998 .{ }^{4}$ León and Soto (1997) allowed up to one break

\footnotetext{
${ }^{1}$ See Table 3 below for the description of GYCPIM and MUV. Our analysis results for the GYCPIM/MUV data are provided in subsection 4.3.

${ }^{2}$ We can easily extend the $\ell_{1}$ trend filtering approach to allow for the presence of piecewise quadratic trends; see Yamada and Yoon (2012a) for an application to U.S. unemployment rate.

${ }^{3}$ Ocampo and Parra-Lancourt (2010) also assumed that the structural break dates are known in their study of the Prebisch-Singer hypothesis.

${ }^{4}$ Zanias (2005) applied the same unit root test with two structural breaks.
} 
and found evidence for negative trends in seventeen series out of twenty-four for all or most of their sample period of 1900-1992. Ghoshray (2012) also applied other unit root tests, allowing for up to two structural breaks. More references are available in Kellard and Wohar (2006), Balagtas and Holt (2009), Arezki et al. (2012), and Yang et al. (2012), among others.

Our results differ substantially from previous ones. We do not specify the number of breaks in advance. The structural break dates are not known a prior, either. The new $\ell_{1}$ filtering method is introduced in the next section.

\section{$3 \quad \ell_{1}$ trend filtering approach}

\subsection{The Hodrick-Prescott filter}

To motivate the new $\ell_{1}$ trend filter, we discuss the Hodrick and Prescott $(1997$, HP) filter first. The HP filter has been widely used to extract the trend components of economic time series data. ${ }^{5}$ The filter estimates the trend component $x_{t}$ of $y_{t}$ by minimizing the following objective function:

$$
\sum_{t=1}^{T}\left(y_{t}-x_{t}\right)^{2}+\lambda \sum_{t=3}^{T}\left(\Delta^{2} x_{t}\right)^{2}
$$

where $T$ is the sample size. The first component measures the errors, $y_{t}-x_{t}$, and the second the smoothness of the trend, $\Delta^{2} x_{t} . \lambda \geq 0$ is a regularization or smoothing parameter that controls the trade--off between the size of the error and the smoothness of the trend.

We may represent (1) as

$$
\|\boldsymbol{y}-\boldsymbol{x}\|_{2}^{2}+\lambda\|\boldsymbol{D} \boldsymbol{x}\|_{2}^{2}
$$

where $\boldsymbol{y}=\left(\begin{array}{lll}y_{1} & \ldots & y_{T}\end{array}\right)^{\prime} \in R^{T}, \boldsymbol{x}=\left(\begin{array}{lll}x_{1} & \ldots & x_{T}\end{array}\right)^{\prime} \in R^{T}$, and $\|\boldsymbol{u}\|_{2}=\left(\sum_{i} u_{i}^{2}\right)^{1 / 2}$ is the Euclidean or $\ell_{2}$-norm of the vector $\boldsymbol{u} . \boldsymbol{D}$ is the second-order difference matrix such that

\footnotetext{
${ }^{5}$ Recently, the HP filter has been used to extract not only trends but business cycle frequency components by applying it twice. See Yamada (2011) and OECD (2011) for more details.
} 
$\boldsymbol{D} \boldsymbol{x}=\left(\begin{array}{lll}\Delta^{2} x_{3} & \ldots & \Delta^{2} x_{T}\end{array}\right)^{\prime} \in R^{T-2}$. Explicitly, $\boldsymbol{D}$ is a tridiagonal and Toeplitz matrix:

$$
\boldsymbol{D}=\left(\begin{array}{ccccc}
1 & -2 & 1 & & \\
& \ddots & \ddots & \ddots & \\
& & 1 & -2 & 1
\end{array}\right) \in R^{(T-2) \times T}
$$

The solution to (1) is denoted as $\boldsymbol{x}^{\text {hp }}$. It can be shown that $\boldsymbol{x}^{\text {hp }}$ is a linear function of the data $\boldsymbol{y}$ :

$$
\boldsymbol{x}^{\mathrm{hp}}=\left(\boldsymbol{I}_{T}+\lambda \boldsymbol{D}^{\prime} \boldsymbol{D}\right)^{-1} \boldsymbol{y}
$$

where $\boldsymbol{I}_{T}$ is an identity matrix of size $T$. Also, as $\lambda \rightarrow 0, x_{t}^{\mathrm{hp}}$ converges to the original data $y_{t}$. Additionally, as $\lambda \rightarrow \infty, x_{t}^{\mathrm{hp}}$ converges to the best affine (straight-line) fit to the data:

$$
x_{t}^{\mathrm{ba}}=\alpha^{\mathrm{ba}}+\beta^{\mathrm{ba}} t
$$

where $\left(\alpha^{\text {ba }} \beta^{\text {ba }}\right)^{\prime}=\left(\sum_{t=1}^{T} \boldsymbol{z}_{t} \boldsymbol{z}_{t}^{\prime}\right)^{-1} \sum_{t=1}^{T} \boldsymbol{z}_{t} y_{t}$ and $\boldsymbol{z}_{t}^{\prime}=\left(\begin{array}{ll}1 & t\end{array}\right)$.

\section{$3.2 \quad \ell_{1}$ trend filtering}

We now discuss the new detrending method proposed by Kim et al. (2009). They suggest minimizing the following objective function:

$$
\sum_{t=1}^{T}\left(y_{t}-x_{t}\right)^{2}+\lambda \sum_{t=3}^{T}\left|\Delta^{2} x_{t}\right|
$$

or, in matrix notation,

$$
\|\boldsymbol{y}-\boldsymbol{x}\|_{2}^{2}+\lambda\|\boldsymbol{D} \boldsymbol{x}\|_{1}
$$

where $\|\boldsymbol{u}\|_{1}=\sum_{i}\left|u_{i}\right|$ denotes the $\ell_{1}$-norm of the vector $\boldsymbol{u}$. Because an $\ell_{1}$-norm appears in the objective function (5), Kim et al. (2009) term their approach $\ell_{1}$ trend filtering.

The objective in (5) or (6) is strictly convex and coercive in $\boldsymbol{x}$, and so has a unique 
minimizer. ${ }^{6}$ Denote the solution to (5) as

$$
\boldsymbol{x}^{\mathrm{lt}}=\left(\begin{array}{lll}
x_{1}^{\mathrm{lt}} & \ldots & x_{T}^{\mathrm{lt}}
\end{array}\right)^{\prime} \in R^{T},
$$

where 'lt' stands for the linear trend. Unlike $\boldsymbol{x}^{\mathrm{hp}}, \boldsymbol{x}^{\mathrm{lt}}$ cannot be expressed analytically, but a numerical solution can be easily derived. We also call $\boldsymbol{y}-\boldsymbol{x}^{\mathrm{hp}}$ and $\boldsymbol{y}-\boldsymbol{x}^{\mathrm{lt}}$ the cyclical components of $\boldsymbol{y}$ from the HP filter and $\ell_{1}$ trend filtering, respectively.

It is well known that including an $\ell_{1}$-norm penalty in objective function (5) leads to a sparse solution. ${ }^{7}$ Therefore, many entries of $\boldsymbol{D} \boldsymbol{x}^{\mathrm{lt}}=\left(\Delta^{2} x_{3}^{\mathrm{lt}} \ldots \Delta^{2} x_{T}^{\mathrm{lt}}\right)^{\prime}$ are zero, which indicates that a piecewise linear trend is obtainable. We give intuitive expositions of this fact later; see (12) below. There are many economic variables for which piecewise linearity is a good approximation for trends, and thus, $\ell_{1}$ trend filtering should find many applications to economic time series. The trends are clearly atheoretical and statistical constructs.

As in the case of the HP filter, when $\lambda \rightarrow 0, x_{t}^{\mathrm{lt}}$ converges to the original data $y_{t}$ and when $\lambda \rightarrow \infty$, it converges to the best affine fit to the data. See Kim et al. (2009, p. 343). They also show that unlike the HP filter, the latter convergence occurs with a finite value of $\lambda$ : for $\lambda \geq \lambda_{\max }$, we have $x_{t}^{\mathrm{lt}}=x_{t}^{\mathrm{ba}}$, see (4), where $\lambda_{\max }=2\left\|\left(\boldsymbol{D} \boldsymbol{D}^{\prime}\right)^{-1} \boldsymbol{D} \boldsymbol{y}\right\|_{\infty}$. Note that $\|\boldsymbol{u}\|_{\infty}=\max _{i}\left|u_{i}\right|$, the $\ell_{\infty}$-norm of the vector $\boldsymbol{u}$.

When $0<\lambda<\lambda_{\max }$, the $\ell_{1}$ trend filtering produces a piecewise linear trend. It is composed of line segments, which are all connected. Consequently, it looks like a bended wire. Let $q$ be the number of the line segments and express the $k$ th segment as

$$
f_{k}(t)=\alpha_{k}+\beta_{k} t, \quad t_{k} \leq t \leq t_{k+1}
$$

where $k=1, \ldots, q$. We set $t_{1}=1$ and $t_{q+1}=T . \alpha_{k}$ and $\beta_{k}$ in (7) are respectively the local

\footnotetext{
${ }^{6}$ See Kim et al. (2009). A continuous function $f: R^{n} \rightarrow R$ is called coercive if $\lim _{\|\boldsymbol{x}\|_{2} \rightarrow \infty} f(\boldsymbol{x})=\infty$. See also Brinkhuis and Tikhomirov (2005) for a general discussion of mathematical optimization.

${ }^{7}$ See Belloni and Chernozhukov (2011) for the use of $\ell_{1}$-norm in high dimensional sparse econometric models.
} 
intercept and slope of the $k$ th interval. Because the line segments are connected at $t=t_{k+1}$,

$$
\alpha_{k}+\beta_{k} t=\alpha_{k+1}+\beta_{k+1} t,
$$

for $k=1, \ldots, q-1$. The connected points, $t_{2}, \ldots, t_{q}$ are called kink points. ${ }^{8}$

It turns out that the relation between the HP filter and $\ell_{1}$ trend filtering, (1) and (5), corresponds to that between the ridge regression and the Lasso (least absolute shrinkage and selection operator) proposed by Tibshirani (1996). For instance, the $\ell_{1}$ trend filtering problem in (5) or (6) is equivalent to minimizing the following $\ell_{1}$-penalized least squares objective function:

$$
\|\boldsymbol{y}-\boldsymbol{A} \boldsymbol{\theta}\|_{2}^{2}+\lambda \sum_{t=3}^{T}\left|\theta_{t}\right|,
$$

where $\boldsymbol{\theta}=\left(\begin{array}{llll}\theta_{1} & \ldots & \theta_{T}\end{array}\right)^{\prime} \in R^{T}$ and $\boldsymbol{A}$ is a lower triangular matrix,

$$
\boldsymbol{A}=\left(\begin{array}{cccccc}
1 & & & & & \\
1 & 1 & & & \\
1 & 2 & 1 & & \\
1 & 3 & 2 & \ddots & & \\
\vdots & \vdots & \vdots & \ddots & 1 & \\
1 & T-1 & T-2 & \cdots & 2 & 1
\end{array}\right) \in R^{T \times T} .
$$

(9) is the Lasso representation of $\ell_{1}$ trend filtering; see p. 345 of Kim et al. (2009). (9) is derived as follows. Define $\boldsymbol{\theta}$ such that $\boldsymbol{x}=\boldsymbol{A} \boldsymbol{\theta}$, and we have $\boldsymbol{D} \boldsymbol{x}=\boldsymbol{D} \boldsymbol{A} \boldsymbol{\theta}=\boldsymbol{\theta}_{3: T}$, where $\boldsymbol{\theta}_{3: T}=\left(\theta_{3} \ldots \theta_{T}\right)^{\prime}$. Therefore, (9) is equivalent to (6). It is noteworthy at this point that $\theta_{1}$ and $\theta_{2}$ are not penalized in (9).

Similarly, it can be easily shown that the HP filter in (1) or (2) is equivalent to minimizing

\footnotetext{
${ }^{8}$ Otero and Iregui (2011) considered other structural break models, in which (8) is not satisfied. See their Figure 1 for their broken linear trend estimation results for the Grilli-Yang data. They allow, however, only one break in the trend.
} 
the following objective function:

$$
\|\boldsymbol{y}-\boldsymbol{A} \boldsymbol{\theta}\|_{2}^{2}+\lambda \sum_{t=3}^{T} \theta_{t}^{2} .
$$

This is the ridge regression representation of the HP filter. See Paige and Trindade (2010).

We can now easily explain why $\boldsymbol{x}^{\text {lt }}$ converges to the best affine fit as $\lambda \rightarrow \infty .{ }^{9}$ When $\lambda \rightarrow \infty, \lambda \sum_{t=3}^{T}\left|\theta_{t}\right| \rightarrow \infty$ unless $\boldsymbol{\theta}_{3: T}=\mathbf{0}_{(T-2) \times 1}$. Therefore, $\boldsymbol{\theta}_{3: T}=\mathbf{0}$ is required to minimize (9). With this requirement, the first component in (9) is

$$
\sum_{t=1}^{T}\left(y_{t}-\theta_{1}-\theta_{2}(t-1)\right)^{2}
$$

This is a simple trend regression, and it explains why we should have an affine fit when $\lambda \rightarrow \infty$. Consequently, as $\lambda \rightarrow \infty$, we have

$$
x_{t}^{\mathrm{lt}}=\left(\theta_{1}^{\mathrm{lt}}-\theta_{2}^{\mathrm{lt}}\right)+\theta_{2}^{\mathrm{lt}} t=\alpha^{\mathrm{ba}}+\beta^{\mathrm{ba}} t
$$

for $t=1, \ldots, T$; see $(4)$.

From $\boldsymbol{D} \boldsymbol{x}^{\mathrm{lt}}=\boldsymbol{\theta}_{3: T}^{\mathrm{lt}}$, we have the following "random walk" relation for $\Delta x_{t}^{\mathrm{lt}}$ :

$$
\Delta x_{t}^{\mathrm{lt}}=\Delta x_{t-1}^{\mathrm{lt}}+\theta_{t}^{\mathrm{lt}}
$$

for $t=3, \ldots, T$, with an initial condition $\Delta x_{2}^{\mathrm{lt}}=\theta_{2}^{\mathrm{lt}}$. Observe that if $\theta_{t}^{\mathrm{lt}}=0$, then $x_{t-2}^{\mathrm{lt}}, x_{t-1}^{\mathrm{lt}}$, and $x_{t}^{\mathrm{lt}}$ are on the straight line and otherwise $x_{t-1}^{\mathrm{lt}}$ becomes a kink point. With larger values of $\lambda, \boldsymbol{\theta}_{3: T}^{\mathrm{lt}}=\left(\begin{array}{lll}\theta_{3}^{\mathrm{lt}} & \ldots & \theta_{T}^{\mathrm{lt}}\end{array}\right)^{\prime}$ generally tends to have more zeros, and vice versa. This observation corresponds to the fact that the number of kink points generally decreases as the value of $\lambda$ increases. (12) also gives us an insight on the slopes of the piecewise linear trend. After

\footnotetext{
${ }^{9}$ This exposition is also valid for the HP filter.
} 
recursive substitution, we have

$$
\Delta x_{t}^{\mathrm{lt}}=\theta_{2}^{\mathrm{lt}}+\sum_{s=3}^{t} \theta_{s}^{\mathrm{lt}}
$$

for $t=3, \ldots, T$. (13) shows that $\theta_{3}^{\mathrm{lt}}, \theta_{4}^{\mathrm{lt}}, \ldots$, and $\theta_{t}^{\mathrm{lt}}$ represent the slope changes. We now provide a simple example by letting $T=7$ and all entries of $\theta_{3: 7}^{\text {lt }}$ be zero except for $\theta_{5}^{\text {lt }}$. In this setting, we have

$$
\Delta x_{t}^{\mathrm{lt}}= \begin{cases}\theta_{2}^{\mathrm{lt}} & t=2,3,4 \\ \theta_{2}^{\mathrm{lt}}+\theta_{5}^{\mathrm{lt}} & t=5,6,7\end{cases}
$$

and a kink point exists at $t=4$.

$\ell_{1}$ trend filtering is flexible enough to be applicable to time series with seasonality, cyclic components, outliers, or occasional level shifts. It can also handle multivariate time series data and even piecewise polynomials. See section 7 of Kim et al. (2009) for more details. For instance, in Yamada and Yoon (2012b), we apply the $\ell_{1}$ filtering method to the U.S. total factor productivity data and examine the changing behavior of their growth rates. We call this approach " $\ell_{1}$ mean filtering." ${ }^{10}$ See also Yamada and Yoon (2012a) for an application of the $\ell_{1}$ piecewise quadratic trend to U.S. unemployment rate. An earlier application of the $\ell_{1}$ trend filtering is in Yamada and Jin (2012) to Japanese GDP.

Finally, all calculations in this paper are carried out using the statistical program Matlab. To implement $\ell_{1}$ trend filtering (5), we use CVX, a package for specifying and solving convex programs, developed by Grant and Boyd $(2008,2011)$. We find CVX to be easy to use. For instance, the following lines implement $\ell_{1}$ trend filtering in (5):

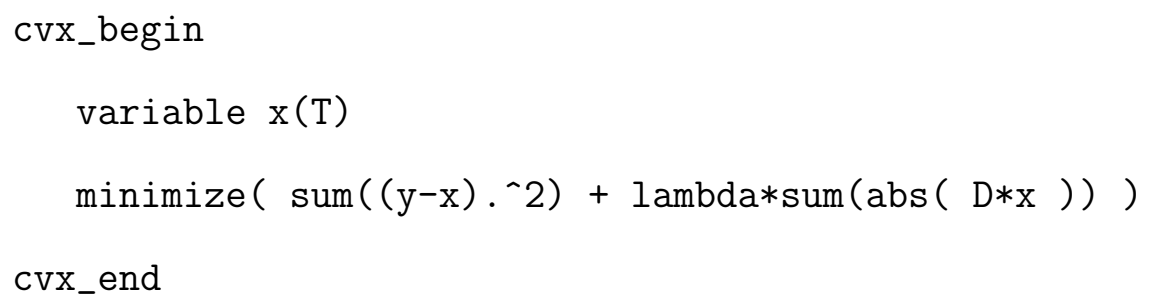

D is defined in (3). ${ }^{11}$ Please visit http://cvxr.com/cvx/ for more details.

\footnotetext{
${ }^{10}$ Tibshirani and Taylor (2011) call this approach 1d fused Lasso.

${ }^{11}$ In Matlab, D = diff $(\operatorname{eye}(\mathrm{T}), 2) ;$
} 


\section{Does the Prebisch-Singer hypothesis hold sometimes?}

\subsection{Data on primary commodity prices}

Figure 1 shows the extended Grilli-Yang data series on the relative prices of twenty-four commodities with logarithms in blue lines. The commodity prices are deflated by the manufacturing unit value [MUV] index. ${ }^{12}$ The sample period is $1900-2010$, a total of 111 observations for the annual data.

[Figure 1 about here]

A list of primary commodities is given in Table 1 for three different categories: Food, nonfood, and metals. The source of the data is http://www.stephan-pfaffenzeller.com/ cpi.html, which is maintained by Stephan Pfaffenzeller. See also Pfaffenzeller et al. (2007) concerning how the original Grilli-Yang data set is extended. We also employ eight aggregate commodity price indexes in section 4.3. See Table 3 for more details on the aggregate price indexes.

\section{2 $\ell_{1}$ piecewise linear trend estimation results}

The estimated $\ell_{1}$ piecewise linear trends of the commodity prices are plotted in Figure 1 with red lines. We set $\lambda=20$ in (5). Their slopes are listed in Table 1 for each price regime. They are the annual growth rates in \%. The years when new price regimes start are also reported in the square brackets. Various numbers of structural breaks are found: two for aluminum and zinc, and seven for cocoa, lamb, jute, wool, and silver, for instance. Note also that a regime can have only one observation, which should be regarded as a transition period to a new regime. Many of the slope estimates are very small. The two steepest ones are for lead and copper after 2000: $8.08 \%$ and $7.24 \%$ per annum, respectively.

[Table 1 about here]

\footnotetext{
${ }^{12}$ Fernandez (2012) considered the effects of different price deflators on the validity of the Prebisch-Singer hypothesis.
} 
Given the large number of structural breaks found in the data, it is not easy to discuss the estimation results in detail for each commodity. Figure 2 shows the periods when the slopes of the estimated piecewise linear trends are found to be negative for each commodity. For example, for aluminum, the slopes of the estimated $\ell_{1}$ piecewise linear trend are all negative: $-2.70 \%$ (1900-1933), $-2.98 \%$ (1934-1948), and -0.60\% (1949-2010). In contrast, they are all positive for timber. Therefore, the Prebisch-Singer hypothesis always holds for aluminum, and does not hold at all for timber. For countries that export aluminum, for instance, their terms of trades have persistently worsened during the last 111 years, and not much gain has been made since 1949 , when the latest regime started. ${ }^{13}$

\section{[Figure 2 about here]}

Additionally, for lamb, tin, and silver, while there are some periods in which the slopes of their trends are negative, the slopes have been positive for most of the sample period. Therefore, we find little evidence for the Prebisch-Singer hypothesis for these three commodities.

For the following eight commodities, the slopes of their trends were negative for most of the sample periods: rice, wheat, maize, bananas, palm oil, cotton, wool, and rubber. Interestingly, they are all food and nonfood primary commodities. Except for maize and cotton, however, the slopes of their piecewise linear trends became positive recently. ${ }^{14}$ Therefore, even though we find strong evidence that the Prebisch-Singer hypothesis sometimes holds for these primary commodities, the strength of the hypothesis becomes somewhat weaker during the last decade or so.

We now examine the changing strength of the Prebisch-Singer hypothesis over the years in more detail. Table 2 provides the number of commodities for which the slopes of their trends are found to be negative in each decade. The evidence for the Prebisch-Singer hypothesis is quite strong during the 1970s and 1980s. However, many series, twelve in total, have changed

\footnotetext{
${ }^{13}$ Aluminum accounts for $20-49 \%$ and $10-19 \%$ of export earnings in Tajikistan and Bahrain, respectively, for 1992-1997; see Cuddington et al. (2007).

${ }^{14}$ According to Krugman (2008), higher oil prices provided an incentive to produce more biofuels, which was responsible for the recent increase in food prices. See also Byrne et al. (2013).
} 
the signs of their trend functions from negative to positive since 1992. For example, rice and rubber, which had negatively sloped piecewise linear trends for about 100 years, now have positively sloped trends. Only nine prices are found to have negatively sloped trends since 2000, and evidence for the Prebisch-Singer hypothesis has recently become much weaker.

[Table 2 about here]

In 1950, when the works by Prebisch and Singer were published simultaneously and independently, negatively sloped trends were observed in less than half of the twenty-four commodities that later comprised the Grilli-Yang data set. Singer (1984) noted, however, that his 1950 thesis was not unduly influenced by the rising trend of the preceding ten years, but by long-term decline in the 1870-1939 period. Given the lack of trends in subsequent years, Williamson (2012) declared that the Prebisch-Singer announcement of secular decline of relative primary commodity prices was premature. At the time when Grilli and Yang (1988) tested the Prebisch-Singer hypothesis with their new data set, many commodities,

which had exhibited positively sloped trends for a long time, had recently turned around into negatively sloped ones: cocoa, sugar, beef, jute, copper, tin, and silver.

Overall, we may conclude that the Prebisch-Singer hypothesis holds sometimes, but not always for most of the primary commodities in the extended Grilli-Yang data set, ending at 2010. The strength of the Prebisch-Singer hypothesis has become substantially weaker in recent years, as the relative prices of many primary commodities increased substantially since about 2000 .

\subsection{Results from aggregate commodity prices}

In this subsection, we estimate the $\ell_{1}$ piecewise linear trends of the eight aggregate primary commodity price indexes. The indexes are listed in Table 3. They are for whole commodities and the subgroups of metals, non-food agricultural commodities, and food commodities, with arithmetic and geometric weights. The commodity price indexes are also deflated by the MUV index. Figure 3 plots the data series with blue lines. 
[Table 3 and Figure 3 about here]

The $\ell_{1}$ piecewise linear trend filtering results are presented in Table 4 , where the estimated slopes of the trends and structural break dates are reported. We again set $\lambda=20$ in (5). Figure 3 plots the estimated piecewise linear trends with red lines and Figure 4 shows the years when the estimated trends are negatively sloped. Interestingly, most aggregate commodity prices exhibited negatively sloped trends for all or most of the sample periods, especially those constructed with arithmetic means. ${ }^{15}$ They also became negative or more negative after around the mid-1970s. Our finding of negative trend for GYCPI agrees well with that in Bunzel and Vogelsang (2005) and Zhou and Shao (2013), whose sample period ended at $1995 .{ }^{16}$ Overall, stronger evidence for the Prebisch-Singer hypothesis is found with the aggregate commodity price indexes.

[Table 4 and Figure 4 about here]

Additionally, the recent movement of metal prices, GYCPIM and GYCPIM-CW, is noteworthy in that they have increased sharply since 2000. The slopes of their trend functions are $3.33 \%$ and $3.17 \%$ per annum, respectively. The increase in metal prices should be attributed to the rapid industrialization and higher demand for metals in China. For instance, Farooki (2012) and Roache (2012) studied the impact on global commodity prices from Chinese demand.

Finally, we test the robustness of the results in subsections 4.2 and 4.3 by employing different values of $\lambda$ in (5). The results do not change substantially and we do not report them here to save space.

\section{Concluding remarks}

In this study, we have asked whether the Prebisch-Singer hypothesis holds sometimes by estimating the piecewise linear trends of the relative primary commodity prices that comprise

\footnotetext{
${ }^{15}$ Cuddington and Wei (1992) found little evidence for trend for the geometric commodity price index.

${ }^{16}$ Bunzel and Vogelsang (2005) found, however, that its trend function was stable over the years.
} 
the famous Grilli-Yang data set. When the slope of the trend is negative, we say that the hypothesis holds locally in the regime.

We apply the newly proposed $\ell_{1}$ trend filtering by Kim et al. (2009) to estimate the trends. A notable feature of $\ell_{1}$ trend filtering is that it produces a piecewise linear trend function of time. The number and dates of structural breaks are not known a priori, and they are simultaneously estimated with the piecewise linear trends.

We find little evidence that the Prebisch-Singer hypothesis always holds in the extended Grilli-Yang primary commodity price data, ending at 2010. For most primary commodities, however, we find that their piecewise linear trends are negatively sloped during some of the sample periods and that the Prebisch-Singer hypothesis holds sometimes. The strength of the hypothesis has become substantially weaker in recent years, as the prices of many primary commodities have increased since around 2000. 


\section{References}

Arezki, Rabah, Kaddour Hadri, Eiji Kurozumi, and Yao Rao, 2012, Testing the Prebisch-Singer hypothesis using second-generation panel data stationarity tests with a break, Economics Letters, 117, 814-816

Balagtas, Joseph V. and Matthew T. Holt, 2009, The commodity terms of trade, unit roots, and nonlinear alternatives: a smooth transition approach, American Journal of Agricultural Economics, 91, 87-105

Belloni, Alexandre and Victor Chernozhukov, 2011, High dimensional sparse econometric models: An introduction, in Inverse Problems and High-Dimensional Estimation, P. Alquier, E. Gautier, and G. Stoltz, (Eds.), 121-156, Lecture Notes in Statistics, volume 203, Springer Berlin Heidelberg

Brinkhuis, Jan and Vladimir Tikhomirov, 2005, Optimization: Insights and Applications, Princeton University Press

Bunzel, Helle and Timothy J. Vogelsang, 2005, Powerful trend function tests that are robust to strong serial correlation, with an application to the Prebisch-Singer hypothesis, Journal of Business and Economic Statistics, 23, 381-394

Byrne, Joseph P., Giorgio Fazio, and Norbert Fiess, 2013, Primary commodity prices: Comovements, common factors and fundamentals, Journal of Development Economics, 101, 16-26

Cashin, Paul and John McDermott, 2002, The long-run behavior of commodity prices: Small trends and big volatility, IMF Staff Papers, 49, 175-199 
Cuddington, John T., Rodney Ludema, and Shamila A. Jayasuriya, 2007, Prebisch-Singer redux, in Natural Resources: Neither Curse nor Destiny, D. Lederman and W.F. Maloney (Eds.), 103-140, The World Bank/Stanford University Press

Cuddington, John T. and Hong Wei, 1992, An empirical analysis of real commodity price trends: aggregation, model selection and implications, Estudios Economicos, 7, 159-179

Deaton, Angus, 1999, Commodity prices and growth in Africa, Journal of Economic Perspectives, $13,23-40$

Farooki, Masuma Zareen, 2012, China's metals demand and commodity prices: a case of disruptive development? European Journal of Development Research, 24, 56-70

Fernandez, Viviana, 2012, Trends in real commodity prices: How real is real? Resources Policy, 37, 30-47

Ghoshray, Atanu, 2011, A reexamination of trends in primary commodity prices, Journal of Development Economics, 95, 242-251

Grant, Michael and Stephen Boyd, 2008, Graph implementations for nonsmooth convex programs, in Recent Advances in Learning and Control (a tribute to M. Vidyasagar), V. Blondel, S. Boyd, and H. Kimura (Eds.), 95-110, Lecture Notes in Control and Information Sciences, Springer, http://stanford.edu/ boyd/graph_dcp.html

Grant, Michael and Stephen Boyd, 2011, CVX: Matlab software for disciplined convex programming, version 1.21, http://stanford.edu/ boyd/cvx 
Grilli, Enzo and Maw Cheng Yang, 1988, Primary commodity prices, manufactured goods prices, and the terms of trade of developing countries: What the long run shows, The World Bank Economic Review, 2, 1-47

Harvey, David I., Neil M. Kellard, Jakob B, Madsen, and Mark E. Wohar, 2010, The PrebischSinger hypothesis: Four centuries of evidence, Review of Economics and Statistics, 92, 367-377

Harvey, David I., Neil M. Kellard, Jakob B, Madsen, and Mark E. Wohar, 2012, Erratum: The Prebisch-Singer hypothesis: Four centuries of evidence, manuscript

Harvey, David I., Stephen J. Leybourne, and A.M. Robert Taylor, 2011, Testing for unit roots and the impact of quadratic trends, with an application to relative primary commodity prices, Econometric Reviews, 30, 514-547

Hodrick, Robert J. and Edward C. Prescott, 1997, Postwar U.S. business cycles: An empirical investigation, Journal of Money, Credit and Banking, 29, 1-16

Kellard, Neil and Mark E. Wohar, 2006, On the prevalence of trends in primary commodity prices, Journal of Development Economics, 79, 146-167

Kim, Seung-Jean, Kwangmoo Koh, Stephen Boyd, and Dimitry Gorinevsky, 2009, $\ell_{1}$ trend filtering, SIAM Review, 51, 339-360

Kim, Tae-Hwan, Stephan Pfaffenzeller, Tony Rayner, and Paul Newbold, 2003, Testing for linear trend with applications to relative primary commodity prices, Journal of Time Series Analysis, 24, 539-551 
Krugman, Paul, 2008, Running out of planet to exploit, New York Times Op-Ed Column, April 21, available at http://www.nytimes.com/2008/04/21/opinion/21krugman.html

León, Javier and Raimundo Soto, 1997, Structural breaks and long-run trends in commodity prices, Journal of International Development, 9, 347-366

Lumsdaine, Robin L. and David H. Papell, 1997, Multiple trend breaks and the unit root hypothesis, Review of Economics and Statistics, 79, 212-218

Ocampo, José and Mariángela Parra-Lancourt, 2010, The terms of trade for commodities since the mid $-19^{\text {th }}$ century, Journal of Iberian and Latin American Economic History, 28, 11-43

OECD, 2012, OECD system of composite leading indicators, manuscript available at http: //www. oecd.org/dataoecd/26/39/41629509.pdf

Otero, Jesús and Ana María Iregui, 2011, The long-run behavior of the terms of trade between primary commodities and manufactures, manuscript

Paige, Robert L. and A. Alexandre Trindade, 2010, The Hodrick-Prescott filter: A special case of penalized spline smoothing, Electronic Journal of Statistics, 4, 856-874

Pfaffenzeller, Stephan, Paul Newbold, and Anthony Rayner, 2007, A short note on updating the Grilli and Yang commodity price index, The World Bank Economic Review, 21, $1-13$

Prebisch, Raúl, 1950, The Economic Development of Latin America and its Principal Problems, New York: United Nations 
Roache, Shaun K., 2012, China's impact on world commodity markets, IMF working paper $12 / 115$

Singer, Hans W., 1950, The distribution of gains between investing and borrowing countries, American Economic Review, 40, 473-485

Singer, Hans W., 1984, The terms of trade controversy and the evolution of soft financing: Early years in the U.N., in Pioneers in Development, G.M. Meier and D. Seers (Eds.), 275-303, The World Bank/Oxford University Press

Tibshirani, Robert, 1996, Regression shrinkage and selection via the lasso, Journal of the Royal Statistical Society, Series B, 58, 267-288

Tibshirani, Ryan J. and Jonathan Taylor, 2011, The solution path of the generalized lasso, Annals of Statistics, 39, 1335-1371

Tilton, John E., 2012, The terms of trade debate and the policy implications for primary product producers, forthcoming at Resources Policy

Williamson, Jeffrey G., 2012, Commodity prices over two centuries: Trends, volatility, and impact, Annual Review of Resource Economics, 4, 185-206

Yamada, Hiroshi, 2011, A note on band-pass filters based on the Hodrick-Prescott filter and the OECD system of composite leading indicators, OECD Journal: Journal of Business Cycle Measurement and Analysis, 2011, 105-109 
Yamada, Hiroshi and Lan Jin, 2012, Japan's output gap estimation and $\ell_{1}$ trend filtering, forthcoming at Empirical Economics

Yamada, Hiroshi and Gawon Yoon, 2012a, Piecewise quadratic trend in U.S. unemployment rate, manuscript

Yamada, Hiroshi and Gawon Yoon, 2012b, High-low-high? Occasional level shifts in U.S. productivity, manuscript

Yang, Chao-Hsiang, Chi-Tai Lin, and Yu-Sheng Kao, 2012, Exploring stationarity and structural breaks in commodity prices by the panel data model, Applied Economics Letters, $19,353-361$

Zanias, George P., 2005, Testing for trends in the terms of trade between primary commodities and manufactured goods, Journal of Development Economics, 78, 49-59

Zhou, Zhou and Xiaofeng Shao, 2013, Inference for linear models with dependent errors, Journal of the Royal Statistical Society, Series B, 75, 323-343 
Table 1: Slopes of the estimated $\ell_{1}$ piecewise linear trends and structural break dates

\begin{tabular}{lrrrrrrrr}
\hline Food & 1 & 2 & 3 & 4 & 5 & 6 & 7 & 8 \\
\hline Coffee & 1.05 & 0.88 & -0.20 & 3.46 & -0.36 & -0.72 & -2.48 & \\
& & {$[1914]$} & {$[1926]$} & {$[1941]$} & {$[1956]$} & {$[1978]$} & {$[1979]$} & \\
Cocoa & -3.95 & -3.28 & -0.35 & 3.92 & 1.33 & -4.69 & -2.11 & 0.68 \\
& & {$[1924]$} & {$[1935]$} & {$[1936]$} & {$[1955]$} & {$[1979]$} & {$[1995]$} & {$[1996]$} \\
Tea & -0.23 & 0.77 & -2.40 & -1.03 & -0.57 & & & \\
& & {$[1920]$} & {$[1960]$} & {$[1993]$} & {$[1994]$} & & & \\
Rice & -0.67 & -0.56 & -3.38 & -1.01 & 0.58 & & & \\
& & {$[1936]$} & {$[1974]$} & {$[1994]$} & {$[2001]$} & & & \\
Wheat & 0.26 & -0.89 & -1.28 & -1.22 & -0.62 & 0.47 & & \\
& & {$[1918]$} & {$[1974]$} & {$[1995]$} & {$[1998]$} & {$[1999]$} & & \\
Maize & 0.53 & -0.30 & -1.01 & -1.46 & -2.41 & -0.68 & & \\
& & {$[1918]$} & {$[1948]$} & {$[1951]$} & {$[1974]$} & {$[1994]$} & & \\
Sugar & -0.81 & -1.05 & -3.12 & 0.07 & -2.41 & -1.84 & -0.17 & \\
& & {$[1917]$} & {$[1918]$} & {$[1934]$} & {$[1975]$} & {$[1993]$} & {$[2000]$} & \\
Beef & 0.91 & 0.79 & 6.23 & 1.19 & -0.52 & & & \\
& & {$[1940]$} & {$[1954]$} & {$[1971]$} & {$[1972]$} & & & \\
Lamb & \multirow{2}{*}{3.25} & 3.41 & -4.12 & 4.72 & 4.29 & 2.32 & 1.88 & 1.16 \\
& & {$[1923]$} & {$[1939]$} & {$[1953]$} & {$[1970]$} & {$[1971]$} & {$[1979]$} & {$[1980]$} \\
Bananas & \multirow{2}{*}{1.38} & 0.42 & -0.38 & -0.82 & -0.84 & 0.71 & & \\
Palm oil & 0.15 & -0.45 & -1.59 & -2.95 & 0.01 & & & \\
& & {$[1917]$} & {$[1966]$} & {$[1967]$} & {$[1993]$} & & & \\
\hline
\end{tabular}




\begin{tabular}{|c|c|c|c|c|c|c|c|c|}
\hline Nonfood & 1 & 2 & 3 & 4 & 5 & 6 & 7 & 8 \\
\hline \multirow[t]{2}{*}{ Cotton } & 0.27 & -0.05 & -2.60 & -2.62 & & & & \\
\hline & & [1919] & [1958] & [1959] & & & & \\
\hline \multirow[t]{2}{*}{ Jute } & 0.71 & 0.24 & 0.76 & -2.72 & -2.85 & -1.45 & 0.46 & \\
\hline & & [1916] & [1937] & [1964] & [1965] & [1995] & [1999] & \\
\hline \multirow[t]{2}{*}{ Wool } & 0.92 & -0.33 & -3.11 & -3.35 & -3.47 & -0.36 & 0.62 & 0.96 \\
\hline & & [1924] & [1952] & [1954] & [1965] & [1994] & [1997] & [1998] \\
\hline \multirow[t]{2}{*}{ Hides } & 0.73 & -1.48 & 0.53 & 0.15 & -1.02 & & & \\
\hline & & [1916] & [1968] & [1992] & [1994] & & & \\
\hline \multirow[t]{2}{*}{ Tobacco } & 3.28 & 1.56 & 0.86 & 0.69 & -0.16 & -0.49 & & \\
\hline & & [1925] & [1936] & [1964] & [1967] & [1968] & & \\
\hline \multirow[t]{2}{*}{ Rubber } & -4.30 & -6.99 & -0.07 & -2.41 & -1.27 & 4.90 & & \\
\hline & & [1911] & [1933] & [1956] & [1993] & {$[2000]$} & & \\
\hline \multirow[t]{2}{*}{ Timber } & 1.98 & 1.03 & 0.90 & 0.43 & & & & \\
\hline & & [1918] & [1954] & [1978] & & & & \\
\hline Metals & 1 & 2 & 3 & 4 & 5 & 6 & 7 & 8 \\
\hline \multirow[t]{2}{*}{ Copper } & -2.02 & 0.45 & 1.54 & -1.42 & 7.24 & & & \\
\hline & & [1935] & [1944] & [1970] & [2000] & & & \\
\hline \multirow[t]{2}{*}{ Aluminum } & -2.70 & -2.98 & -0.60 & & & & & \\
\hline & & [1934] & [1949] & & & & & \\
\hline \multirow[t]{2}{*}{ Tin } & 0.41 & 1.88 & -5.46 & -4.71 & 5.07 & & & \\
\hline & & [1947] & [1980] & [1998] & [1999] & & & \\
\hline \multirow[t]{2}{*}{ Silver } & -1.78 & 1.49 & 1.96 & 2.07 & 3.56 & -4.05 & -3.60 & 5.35 \\
\hline & & [1945] & [1949] & [1955] & [1957] & [1981] & [1997] & [1998] \\
\hline \multirow[t]{2}{*}{ Lead } & 0.10 & 0.59 & -0.52 & -1.85 & -2.46 & -1.74 & 8.08 & \\
\hline & & [1935] & [1956] & [1969] & [1970] & [1995] & [2000] & \\
\hline \multirow[t]{2}{*}{ Zinc } & -0.56 & 0.23 & 0.92 & & & & & \\
\hline & & [1932] & [1999] & & & & & \\
\hline
\end{tabular}

The sample period is 1900-2010. The slopes are the annual growth rates in \%. The estimated year when a new regime starts is reported in square brackets. See also Figure 1. 
Table 2: The strength of the Prebisch-Singer hypothesis in each decade

\begin{tabular}{lr}
\hline decade & number \\
\hline $1900 \mathrm{~s}$ & 9 \\
$1910 \mathrm{~s}$ & 9 \\
$1920 \mathrm{~s}$ & 14 \\
$1930 \mathrm{~s}$ & 13 \\
$1940 \mathrm{~s}$ & 12 \\
$1950 \mathrm{~s}$ & 10 \\
$1960 \mathrm{~s}$ & 14 \\
$1970 \mathrm{~s}$ & 17 \\
$1980 \mathrm{~s}$ & 20 \\
$1990 \mathrm{~s}$ & 20 \\
$2000 \mathrm{~s}$ & 9 \\
\hline
\end{tabular}

$\stackrel{\sim}{\triangleright} \quad$ In each cell, the number of commodities is reported for which the Prebisch-Singer hypothesis holds in each decade. The total number of commodities is twenty-four. 
Table 3: Description of the aggregate commodity price indexes

\begin{tabular}{ll}
\hline GYCPI & Grilli and Yang commodity price index \\
GYCPIM & Metal sub-index \\
GYCPINF & Non-food agricultural commodities sub-index \\
GYCPIF & Agricultural food commodities sub-index \\
GYCPICW & Grilli and Yang commodity price index, geometric aggregation \\
GYCPIM-CW & GYCPIM, geometric aggregation \\
GYCPINF-CW & GYCPINF, geometric aggregation \\
GYCPIF-CW & GYCPIF, geometric aggregation \\
MUV & MUV-G5 unit value index \\
\hline
\end{tabular}

MUV-G5: a trade--weighted index of the five major developed countries' (France, Germany, Japan, the U.K., and the U.S.) exports of manufactured commodities to developing countries.

The above description is taken from Pfaffenzeller et al. (2007). 
Table 4: Slopes of the estimated $\ell_{1}$ piecewise linear trends and structural break dates of aggregate commodity prices

\begin{tabular}{lrrrrrr}
\hline data & 1 & 2 & 3 & 4 & 5 & 6 \\
\hline GYCPI & -0.92 & -0.47 & -0.63 & -1.09 & -0.35 & \\
GYCPIM & & {$[1934]$} & {$[1974]$} & {$[1975]$} & {$[1999]$} & \\
GYCPINF & -1.81 & 0.42 & -0.90 & 3.33 & & \\
& -1.36 & -0.54 & -0.63 & & & \\
GYCPIF & & {$[1946]$} & {$[1972]$} & {$[2000]$} & & \\
& -0.34 & -1.97 & -0.80 & & & \\
GYCPICW & & {$[1975]$} & {$[1995]$} & & & \\
& -0.13 & -0.08 & -1.15 & -0.72 & & \\
GYCPIM-CW & -1.37 & {$[1935]$} & {$[1974]$} & {$[1999]$} & & \\
& & 0.71 & -0.80 & -1.10 & -0.49 & 3.17 \\
GYCPINF-CW & 0.50 & 0.21 & -0.59 & & & \\
& & {$[1945]$} & {$[1972]$} & {$[1975]$} & {$[1999]$} & {$[2000]$} \\
GYCPIF-CW & -0.08 & 0.05 & -2.00 & -0.99 & & \\
& & {$[1935]$} & {$[1975]$} & {$[1994]$} & & \\
\hline
\end{tabular}

The sample period is 1900-2010. See also Tables 1 and 3, and Figure 3. 
Note for Figure 1

The blue line shows the data and the red line plots the estimated $\ell_{1}$ piecewise linear trend. See also Table 1. 
Figure 1: Primary commodity prices and their piecewise linear trends, 1900-2010
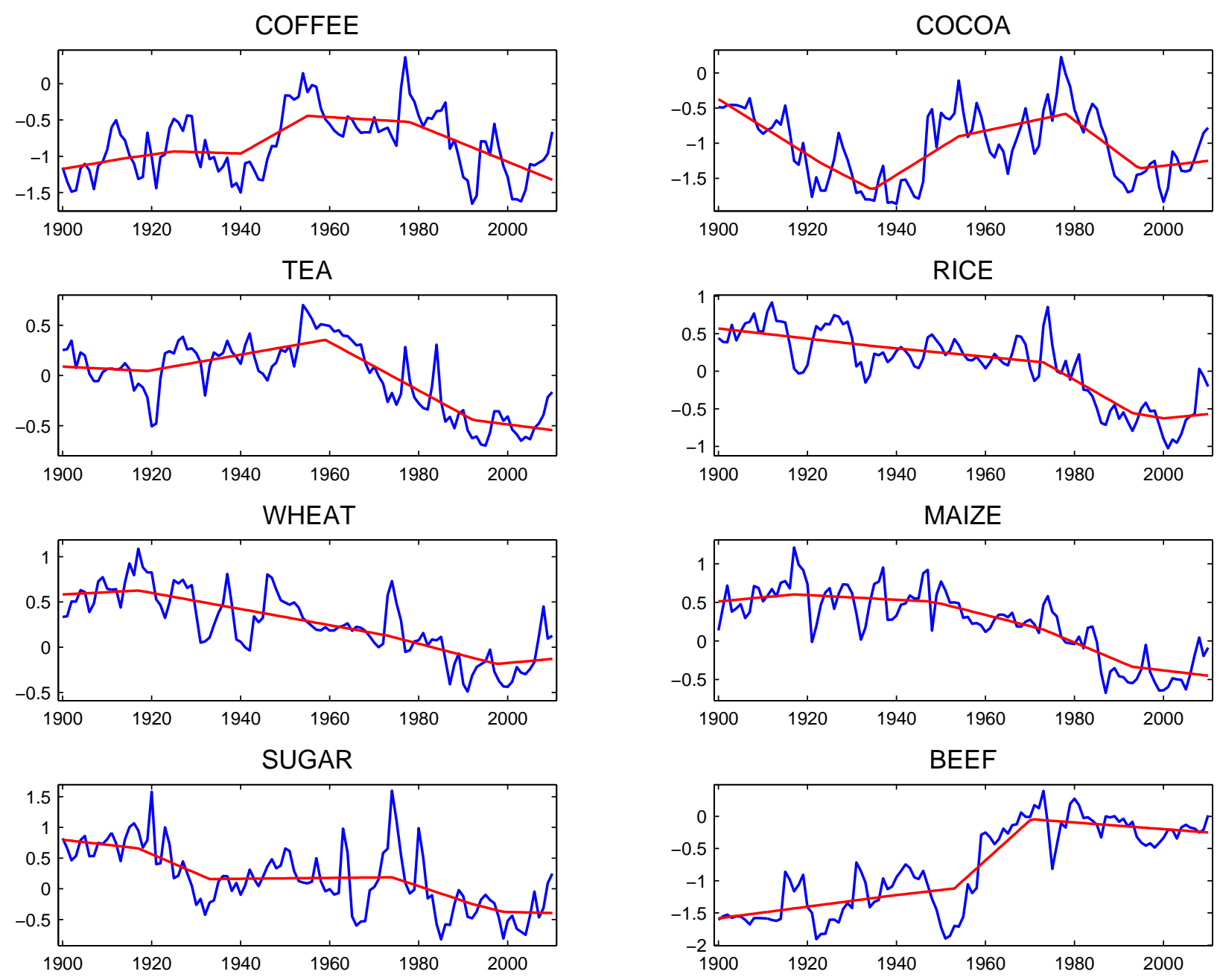
LAMB
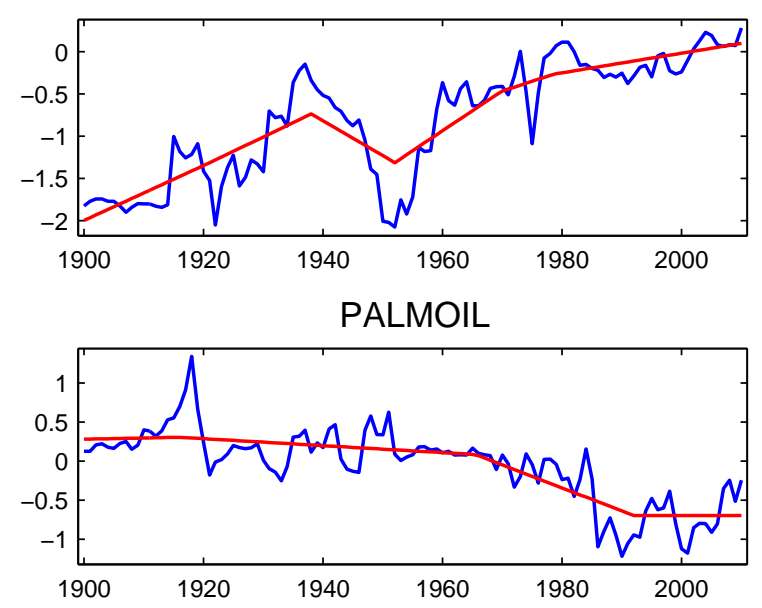

BANANAS
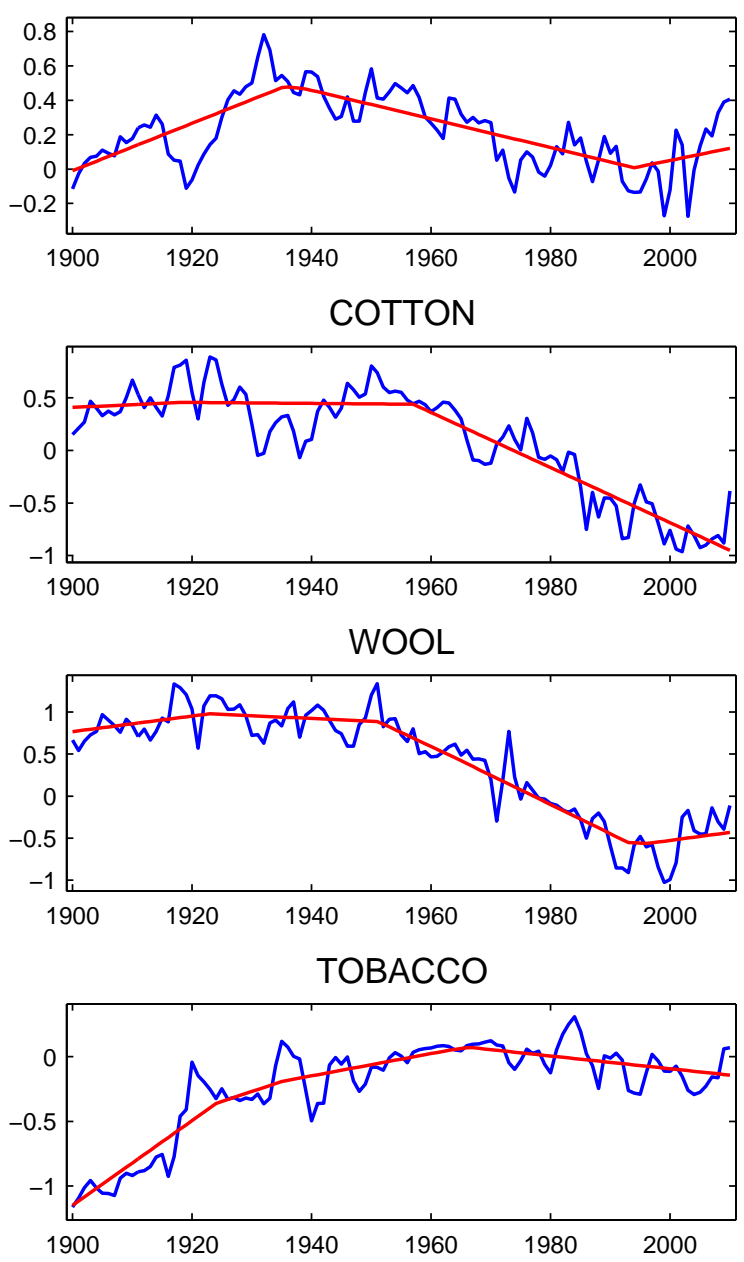
RUBBER
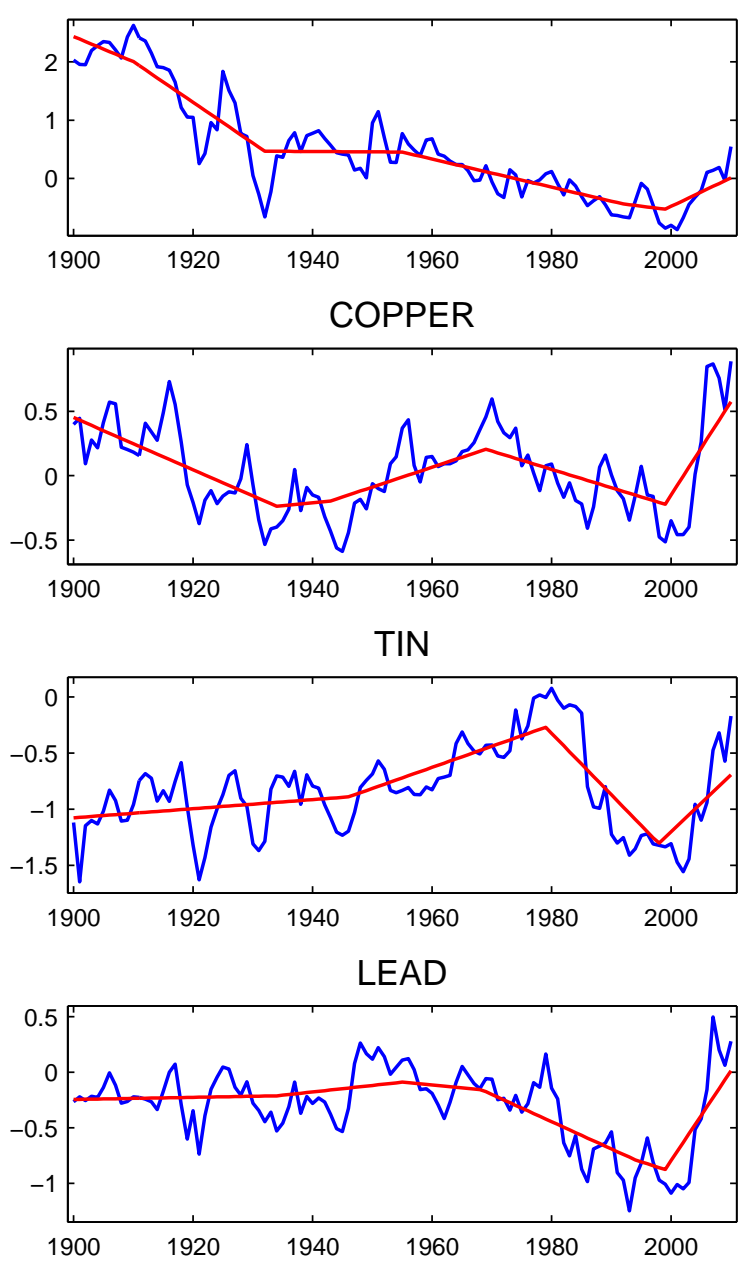

TIMBER
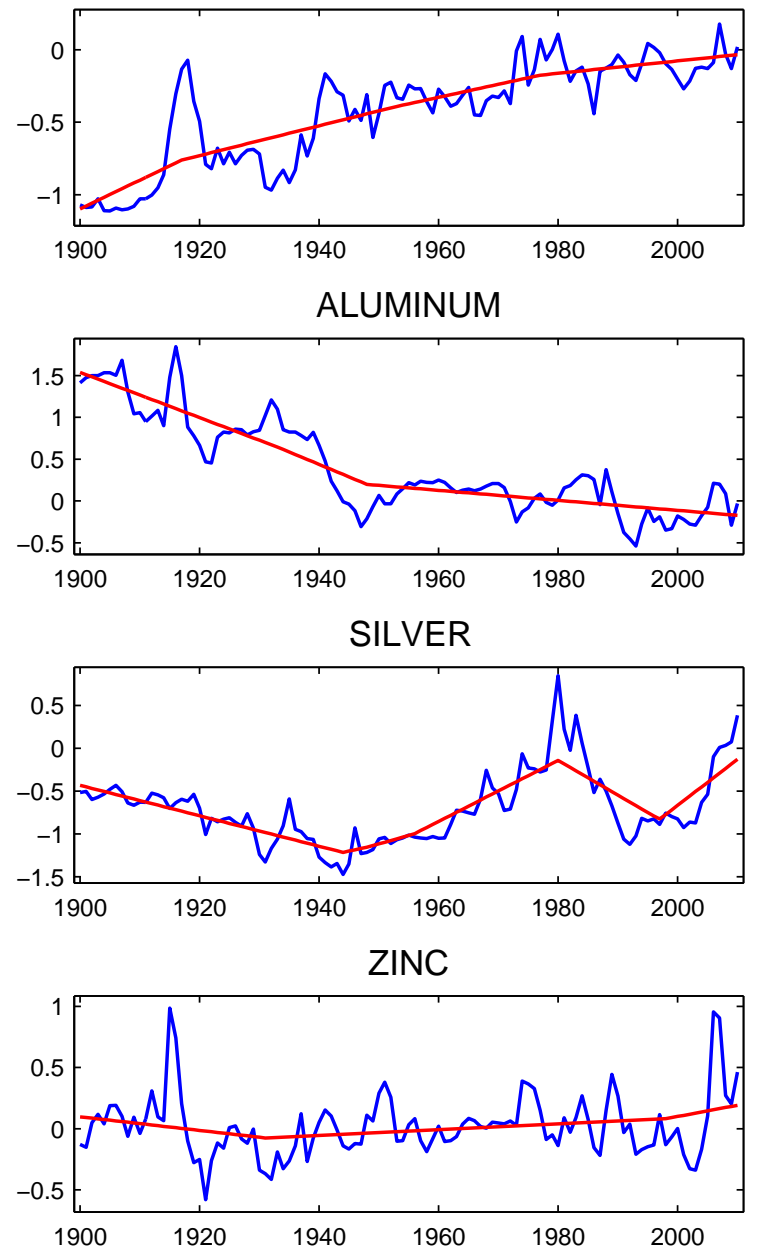
Figure 2: Years when the piecewise linear trends are negatively sloped

The dotted lines indicate the years when the $\ell_{1}$ piecewise linear trends are negatively sloped for each commodity. 
Years when the piecewise linear trends are negatively sloped

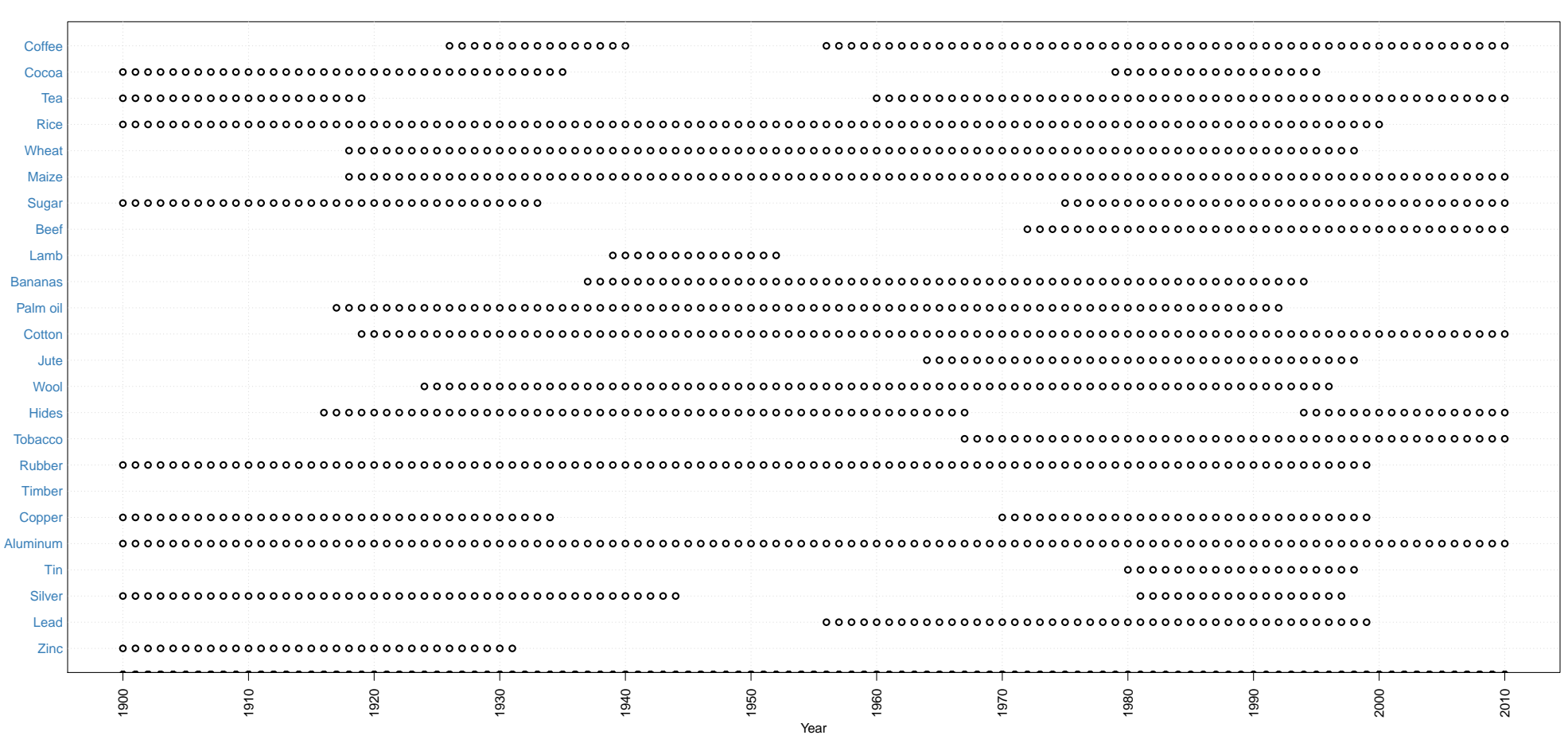


Figure 3: Aggregate primary commodity prices and their piecewise linear trends, 1900-2010

See also Figure 1 and Table 3. 

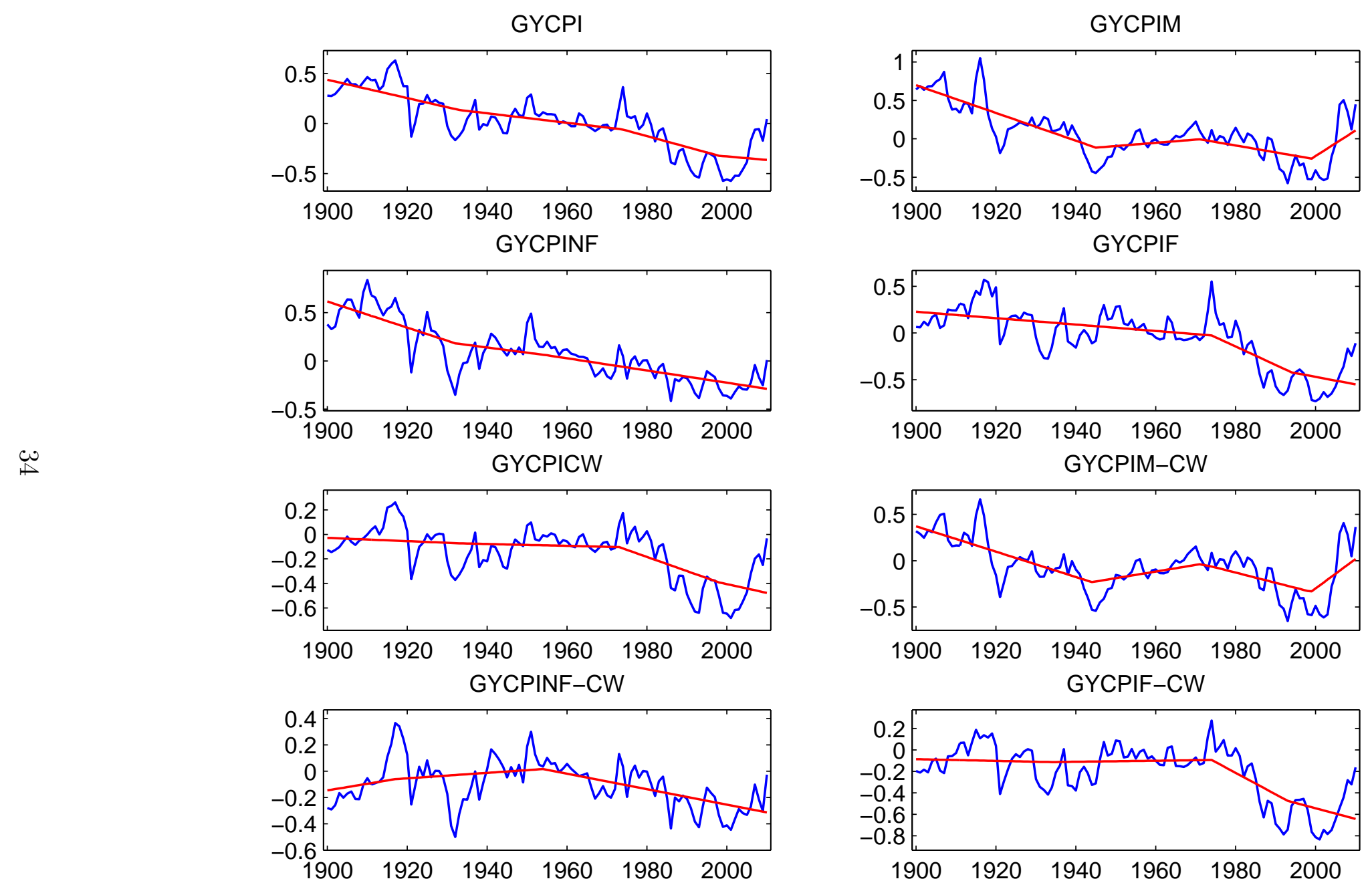
Figure 4: Years when the piecewise linear trends are negatively sloped for aggregate commodity prices

See also Figure 2. 
Years when the piecewise linear trends are negatively sloped for aggregate commodity prices

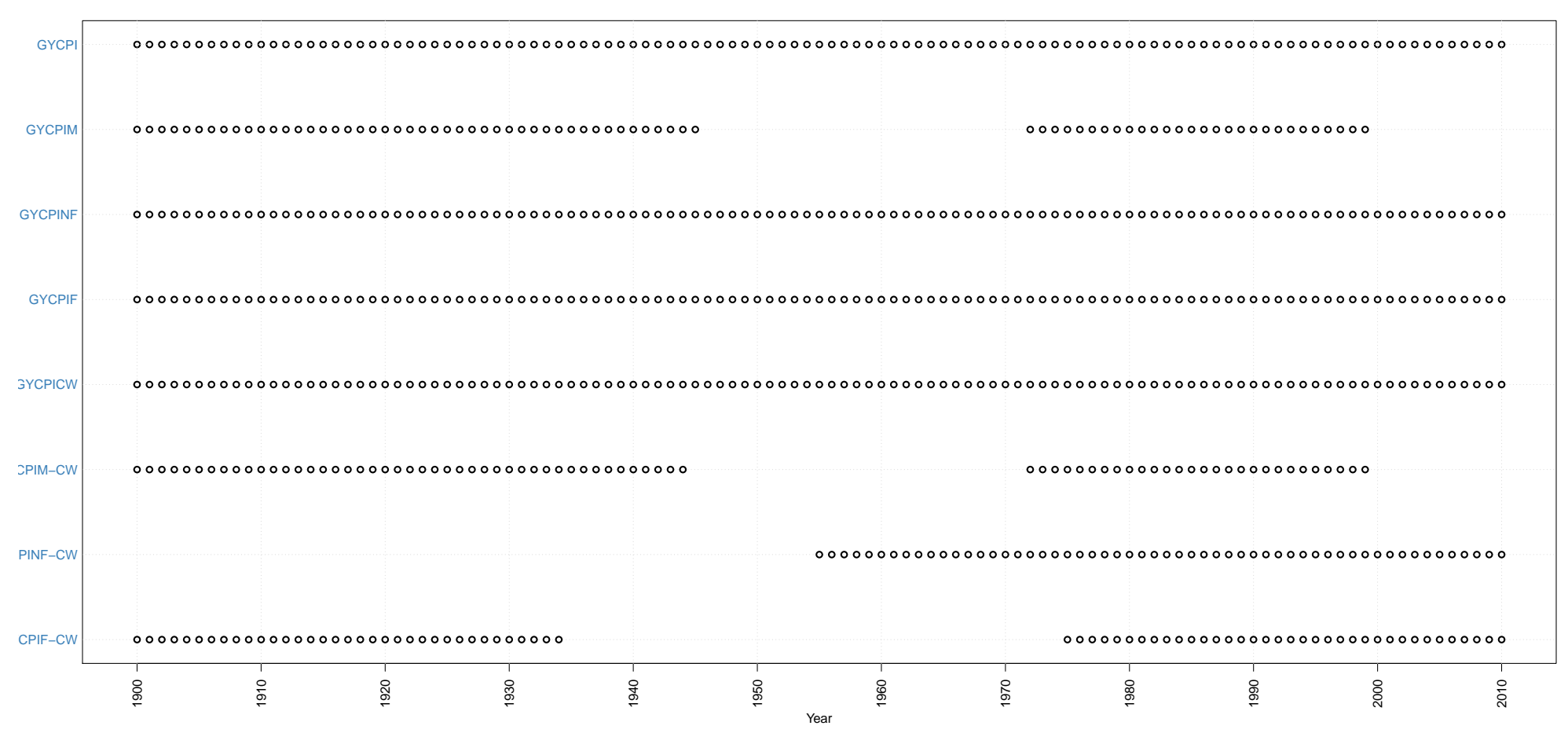

